\title{
Use of Drip Irrigation in Orchards
}

\author{
B. Bravdo ${ }^{1}$ and E.L. Proebsting ${ }^{2}$
}

Additional index words. water, root restriction, mineral uptake, water distribution, soil aeration, root/shoot relation, scheduling

Summary. The use of drip irrigation in orchards is increasing worldwide. Water shortage, prevention of ground water contamination, and improved production are the main reasons for this increase. The combination of partial wetting of the soil and control of the water penetration depth considerably increases the efficiency of irrigation. Recent technological improvements permit maintenance of a constant volume of irrigated soil in which gradients of soil water matric potentials and mineral concentrations exist from the irrigation point to the margins of the wetted zone. Because water and mineral uptake is a function of soil matric potential and mineral concentration, respectively, optimal uptake rates by certain portions of the root system always exist along these gradients for any given environmental conditions. Gradients of air concentration act similarly and permit maintenance of high water availability without any interference with root aeration. Due to the relative ability of the roots to exchange water, minerals, and, possibly, oxygen, the entire root system functions more efficiently compared to root systems under conventional irrigation methods. Physiological root restriction effects induce the formation of a large number of small roots with frequent branching. Consequently, the relative surface area for water and mineral absorption is increased several-fold, and the increased number of root tips that are known to be involved in production of hormones (such as gibberelins and cytokinins) is significant. Evidence for enhanced fruit bud formation under conditions of root restriction is presented here. Water treatment and filtration technology has improved, and

${ }^{1}$ Hebrew Unipersity of Jerusalem, POB 12, Rehovot 76100 , Israel.

${ }^{2}$ Irrigated Agriculture Research and Extension Center, Route 2, Box 2953-A, Washington State Univ., Prosser, WA 99350-9687.

clogging of surface or buried drip systems now can be minimized, which also increases the suitable range of water quality for use in drip systems.

\section{Drip irrigation concepts and principles}

The introduction of localized irrigation methods (drip and microsprinklers) during the past 3 decades has proved that some of the principles commonly applied to conventional irrigation methods do not necessarily apply to microirrigation, and may limit optimization of fruit production. These differences include: 1) Uneven distribution of water and its relationship to water availability; 2) a relationship between water availability and soil aeration; 3) uneven distribution of minerals; and 4) uneven distribution of of roots and physiological effects of root restriction. Because drip systems most appropriately represent the principles and concepts of localized irrigation, as compared to microsprinklers, the following discussion concentrates on drip irrigation.

Uneven distribution of water and water availability. The water distribution under each dripper forms a bulb-shaped zone where most of the irrigated soil is under the soil surface. The width of the wetted "bulb" depends mainly on the hydraulic conductivity of the soil, whereas the depth is a function of both saturated hydraulic conductivity and gravity. For this reason, the vertical axis of the water distribution is usually longer than the horizontal axis. The horizontal/vertical length ratio is correlated positively with the hydraulic conductivity of the soil, and the ratio is higher in finertextured soils. Because the water distribution is uneven, there is always a gradient between the irrigation point where the soil is water-saturated and the margins of the irrigated soil where the soil may vary from near wilting 
point (WP) in arid climates. to fairly moist in higher rainfall areas. Due to this nonuniformity it is very hard to define a single value to represent the water content of the soil. Integration of the values along the gradients is meaningless because each single root along this gradient is subject to a different soil water potential (SWP). Because water uptake rate varies with SWP, it is likely that the rate of water uptake by roots varies according to their location along the SWP gradient. Because water moves along water potential gradients within the root system (Taylor and Fenn, 1985), it is likely that, at any given time, at least part of the root system is subject to optimal SWP for water uptake.

The maximum capability of the roots to absorb water depends on their surface area, which is a function of their length, number, and diameter. Small roots have a relatively high surface area per unit of cross-sectional area or per unit of root mass. A large mass of small rootlets will, therefore, have a surface area that is a few orders of magnitude greater than an equivalent mass of large-diameter roots.

In summary, a high concentration of small rootlets in the confined volume ofirrigated soil under the dripper may have a tremendous capacity to supply water to the above-ground canopy due to increased root surface area, a relatively low dependence on water movement in the soil, a continuous provision of at least part of the root system to optimal SWP, and transfer of water between wet and dry roots. Such root systems are likely to be formed under drip conditions provided that high water availability (Bravdo et al., 1992), aeration (Richards, 1986), and appropriate nutrient concentrations (Bravdo et al., 1992; Richards, 1986) prevail. Water availability can be maintained by frequent irrigation applications. Aeration and mineral concentration are discussed below.

Aeration. Aeration in the root environment is needed for respiration. Plant organs of fruit trees cannot function normally under sustained anaerobic conditions because interference with the respiration process impairs the energy production and use necessary for maintaining processes such as cell elongation and division, hormone production, mineral absorption, etc.

Water availability and soil aeration are inversely related to each other because water fills up the air space between the soil particles, thereby pushing out the air during the irrigation process. This seems to be a correct assumption for all irrigation methods that wet most of the soil surface. However, in drip irrigation, there is always a gradient of soil water potential from the irrigation point toward the margins of the irrigated soil volume and, conversely, an opposite gradient of air from the margins to the irrigation point. Similar to what was described above for water, there is also a nonuniform distribution of air in the root zone, thereby subjecting various parts of the root system to a range of of air concentrations. Unfortunately, not much is known about optimal concentrations of air, or, more precisely, of oxygen for fruit tree roots.

It is interesting to note that, in practice, many orchards are irrigated daily by drip for as much as 10 to $12 \mathrm{~h}$ continuously without showing any waterlogging effects such as iron-induced chlorosis, stunted growth, wilting, or phytophthora root rots. Ordinarily, no incipient wilting symptoms are observed, even under extremely high evaporative demand conditions, and fruits tend to show faster sugar accumulation rate and intensified acid metabolism (Safran et al., 1974; Van Zyl, 1984), as well as better texture and firmness (Safran et al., 1974), under high-frequency drip irrigation. Moreover, to the best of our knowledge, no root damage or decay has been reported in orchards drip-irrigated daily, even directly under the emitter, where continuous soil water saturation exists over periods of weeks or months.

Therefore, unlike other irrigation methods, no interference between water availability and soil aeration appears to exist in drip-irrigated orchards. This advantage might explain observations of advanced maturation and enhanced quality of fruit from drip-irrigated trees.

The mechanism behind this effect might be connected to oxygen transfer from the roots located at the interface between the dry and the wet soil, where the exposure to air is abundant, to roots in the water-saturated area directly under the dripper. Data is lacking in the literature concerning rate of air or oxygen transfer among fruit tree roots. In principle, this phenomenon is known to occur in quite a few plant species. Field observations made in Israel showed that daily drip irrigations in which water was applied at the rate of consumptive use reduced the extent ofiron-induced chlorosis of apples grown on fine-textured soils as compared to 3- and 6-day intervals of drip irrigation (Ein Gal, 1982).

A possible explanation of this phenomenon is the existence of a permanent root concentration well-exposed to air at the interface between the irrigated and the nonirrigated soil when daily irrigation at the rate of consumptive use is practiced. Longer irrigation intervals, which do not maintain a constant volume of irrigated soil but rather flood the majority of the root system by swelling and shrinking of the irrigated soil volume (between irrigations), is more likely to result in anoxic periods. This also might explain the better fruit quality with regard to size and storage potential obtained by daily vs. weekly drip irrigation in fine-textured clay soils (Ein Gal, 1982). Similarly, a faster rate of sugar accumulation and advanced maturation of drip as compared to microjet-irrigated vines (Van Zyl, 1984) also may be attributed to the concomitant effect of high water availability and adequate aeration.

Mineral nutrition. A lthough minerals constitute $<10 \%$ of a plant's dry weight, their level and composition in various plant organs is of primary importance regarding the control of various physiological processes related to production and quality of agricultural commodities. The major constituents of plants are organic, and depend quantitatively and qualitatively on the unique ability of plants to fix atmospheric $\mathrm{CO}_{2}$ via photosynthesis. This process is regulated by environmental factors, including light, temperature, air humidity, $\mathrm{CO}_{2}$ concentration on one hand and on plant factors such as tissue hydration, mineral content and composition, and genetic factors, on the other. The mineral requirements for optimal production varies in many cases at various stages of growth and development, including germination, vegetative growth, fruit bud differentiation, flower and fruit growth, etc. Controlling mineral availability in field-grown plants is difficult due to interactions with the chemical and physical properties of the soil, as well as the variability of root distribution. 
However, low-volume, high-frequency irrigation methods, such as drip, may be used to concentrate the roots in a relatively small volume of soil, thereby making them less affected by soil heterogeneity. When applying soluble fertilizers through the irrigation water (fertigation), the various fertilizer components are distributed unevenly because of their different mobilities in the soil. $\mathrm{NO}_{3}-\mathrm{N}$ moves with the water and tends to accumulate at the edges of the wetted zone, whereas $\mathrm{NH}_{3}-\mathrm{N}, \mathrm{P}$, and $\mathrm{K}$ do not move well in the soil and tend to accumulate in the vicinity of the dripper, forming decreasing gradients towards the margins of the wetted soil volume (Phene and Beale, 1976; Raushchkolb et al., 1976; Uriu et al., 1977).

The interaction of all the dynamic processes occurring under frequent drip fertigation conditions creates a dense root concentration composed of numerous small rootlets and root tips, with a fast turnover, extensive ramification, and an increased root surface area that greatly enlarges the potential for mineral and water absorption. Due to the existing gradients of the minerals, oxygen, and water, various parts of the root system are subject to different environmental conditions under which mineral uptake rates can vary from zero to maximum, depending on their concentrations, soil water potential, and aeration. Basically, the rate of uptake of each mineral is a function of its concentration in the root medium for any given environmental conditions (Epstein, 1972). The use of drip fertigation opens new possibilities for using fertilization programs based on concentrations of fertilizers in the root zone rather than the common method of weight units per plant or per area (i.e., pounds per acre, kilograms per hectare). This approach also is used when growing plants in hydroponics, where terms such as fullstrength, half-strength nutrient solution, etc., are used rather than weight units of individual elements. Due to the close contact between the roots and the nutrient solution in the soil, the uptake of minerals is more efficient as compared to conventional methods of irrigation, and fertilization control of various mineral levels in the leaves can be achieved easily and quickly (Bravdo and Hepner, 1987; Uriu et al., 1980).
It should be kept in mind, however, that, due to the intensive occupation of the soil by the roots, the rate of mineral depletion is also faster, and the plants depend more on the minerals applied by fertigation and have less access to native minerals of the soil. This sometimes may be a shortcoming, but it also can be an advantage for the following reasons: 1) Soil chemical composition is not always well-balanced, and it is well-known that plants grow better on artificial media with complete nutrient solutions; and 2) the relatively fast depletion ofminerals in the confined soil volume efficiently occupied by roots enables one to change rapidly the concentration of any given element during the growing season by either adding or eliminating certain elements.

Depending on the plant species, various elements are required at various stages of growth and development throughout each growing season as well as at various ages of perennial plants. Rapid vegetative growth is needed for most fruit trees during the first years after planting in order to build up the tree skeleton and thereby prepare the tree for early production, whereas controlled vegetative growth often is needed to induce fruit bud formation (Richards, 1986). Similarly, it is always important to maintain a proper fruit weight to leaf area ratio to ensure fruit quality and maintain optimal production. In most cases, it may be easier to control vegetative growth than fruit bud formation and other related factors, such as fruit set and abscission, by controlling the mineral concentration and composition in the root zone. Soil and tissue analyses normally guide fertilizer application rates.

Maintaining high $\mathrm{N}$ concentrations in the root zone can stimulate vegetative growth, particularly at the beginning of the season, provided no limiting factors, such as other mineral deficiencies, exist. Stimulating vegetative growth by $\mathrm{N}$ application reduces crop load by increasing the leaf area : fruit ratio. Canopy size is established early in the season before the fruit starts accumulating sugars and becomes a major sink that competes with the growing shoot tips for assimilate production in the leaves. The crop load can be estimated from the ratios of leaf area to fruit weight (Kliewer and Weaver, 1971), fruit weight to trunk cross-sectional area increment (Assaf et al., 1974, 1985), total cross-sectional area of the trunk (Ferree, 1980), or crop : pruning weight ratio in grapevines (Bravdo et al., 1985). The best fruit quality is obtained when fruit ripening processes occur under conditions of sufficient leaf area and minimal vegetative growth. It is easier to control vegetative growth by $\mathrm{N}$ fertilization in sandy soils than in fertile soils because, in the first case, the feeder root system that develops under the drippers is more dominant as a source for native nutrients to the plants. This is probably one of the reasons why drip is more advantageous than conventional irrigation methods in sandy soils.

Root to shoot relationship. The importance of roots as growth regulator producers rather than solely water and mineral absorbers was investigated intensively during the past decade (Davies and Zhang, 1991; Richards, 1986). The major hormonal regulators produced in the roots are cytokinins, gibberelins, and abscisic acid. These hormones are involved in vegetative and reproductive growth as well as stomatal function and dormancy. Most of their production is in the root tips and is connected with meristematic activity. Thus, growth regulator production is correlated positively with root activity or, more precisely, with the rate of branching and root tip formation. It seems, therefore, that studies of root/shoot interactions should be based on number of root tips and root surface area rather than on root dry weight, as is commonly used.

Woody plants grown in small containers that restrict their root systems to a small volume of soil normally are dwarfed, precocious, and exhibit a very rapid root turnover rate, provided water and mineral availability are well-maintained. (Richards, 1986; Salomon, 1979). The mechanism by which root hormone production affects growth and differentiation is not understood fully; however, the involvement of root cytokinins and gibberellins in these processes is well-established.

Daily drip irrigation, which limits the root system to a confined volume of soil, creates physiological root restriction effects resembling those formed in container-grown trees. This is reflected in an increase in reproductive : vegetative growth ratio, and may impose overcropping in young peach trees (Richards, 1986) as well as in 
bearing orchards where root restriction was imposed by either reducing the volume of the irrigated soil (Assaf et al., 1988) or by conversion from sprinklers to drip (Bravdo et al., 1992). However, in these three cases, the effect was transitional and fruit size recovered after one to three seasons, when the balance between vegetative and reproductive growth was reestablished.

The ability of trees to adjust to conditions of root restriction greatly depends on the rate of root formation under the drippers. Speeding up this process requires correct management of fertigation by closely controlling the availability of water and minerals in the root zone, as well as frequent tissue analyses to adjust the fertilizer applications to the plant needs. In practice, we have seen many cases where no transitional stage was apparent when bearing orchards were converted from traditional irrigation methods to drip. Middleton et al. (1979) also found increased precocity, fruiting efficiency, and total soluble solids (TSS) of apples when roots were restricted by drip irrigation or by growing them in small lysimeters.

\section{Technological aspects of drip irrigation}

The water consumption of trees is determined by canopy size and structure and by meteorological conditions, rather then by the volume of the irrigated water. Therefore, drip irrigation that wets only part of the orchard's soil volume does not necessarily reduce the water consumption of trees, but rather increases the efficiency of water use by cutting back water waste due to evaporation, water percolation, and competitive consumption by weeds.

Most drip systems in orchards are designed to emit 0.5 to $1.5 \mathrm{~mm} / \mathrm{h}$. Therefore, orchards grown in warm regions with ET rates of 7 to $10 \mathrm{~mm} /$ day need about 7 to $14 \mathrm{~h}$ /day of continuous irrigation to satisfy this demand. Scheduling irrigation intervals of 4 to 7 days, therefore, will require continuous irrigation for a few days. This no doubt will result in water percolation to soil layers below the effective root zone. In addition, decreasing the irrigation efficiency will leach fertilizers into the groundwater. The soil cannot serve as a major water reservoir under drip because of the small wetted soil volume. Any attempt to increase it very likely will result in water percolation to layers below the main root zone; therefore, daily irrigation is advantageous and recommended.

The risk of stress effects due to temporary power loss, etc., is not as high as one might expect due to the capability of water exchange between roots and the existence of roots beyond the drip-irrigated zone. Such roots provide water under stress conditions, whereas in normal regimes, water is taken up preferentially by the active drip-type roots concentrated in the upper soil layers. However prolonged periods ofdrought might cause more stress damage as compared to conventional irrigation methods.

It is a well-established that daily drip irrigation does not interfere with aeration (Bravdo et al., 1992). On the contrary, irrigation at longer intervals causes successive swelling and shrinkage of the irrigated soil volume (as opposed to daily irrigation, where the the size and the shape of the wetted soil volume is more or less constant), thereby flooding the entire root system-often due to additional factors such as ponding and run off.

Tensiometers are efficient and convenient tools for controlling irrigation. They should not be used to determine when to irrigate, but rather to fine-tune the daily amount of irrigation water as applied by using evapotranspiration (ET) coefficients. At least two tensiometers should be used at each station: one at about $30-\mathrm{cm}$ and one at $80-$ to $90-\mathrm{cm}$ depths, with the number of stations depending on the uniformity of the soil and the orchard. The upper tensiometer should be at a constant 10 to $20 \mathrm{~cm}$ from the emitter across the orchard. Maintaining a constant reading at any point in the upper soil layer will result in a constant irrigation volume. Any point that reads between 10 and $20 \mathrm{kPa}$ is appropriate. If the ET values used are too high or too low, the readings of this tensiometer will increase or decrease, respectively. The second tensiometer should be placed at about $15 \mathrm{~cm}$ radial distance from the dripper. Readings $<10 \mathrm{kPa}$ at the 80 - to $90-\mathrm{cm}$ depths indicate that water is moving downward. Automated irrigation can be based on climatic data on average readings of electrotensiometers, or any other reliable soil moisture sensors using an irrigation computer for screening, averaging, and controlling the irrigation system (Assaf et al., 1988; Bravdo at al., 1992).

Selecting the appropriate drip system. Drip irrigation systems consist mainly of a conveyance/distribution systems and emitters. The most appropriate spacing of the emitters depends mainly on the soil characteristics rather than on the type of trees or planting distances. Because the concentration of the feeder roots is correlated with their distance from the dripper rather than with the distance from the tree (Levin at al., 1979), it is most appropriate to space emitters uniformly along the dripper line. Spacing distances should be aimed at forming a continuous strip of wetted soil along the drip line. Due to the bulb shape of the water distribution under the drippers, continuity will be formed at the depth where the maximum diameter of the bulb shape occurs, rather than on the soil surface.

A very common spacing combination that fits quite a wide range of soil types is 4-liters/h drippers spaced $1 \mathrm{~m}$ apart. In silty-clay soils, a 1.2- to $1.5-\mathrm{m}$ spacing often is used, whereas 2 liters $/ \mathrm{h}$ at 0.5 to $0.7 \mathrm{~m}$ is used in sandy soils. The most appropriate spacing $\mathrm{x}$ rate of emission combination can be predicted from soil physical analysis data (Bresler, J977).

In cases of variability in soil or in tree size due to replanting, it is possible to use various combinations of emitter flow rate and spacing. Because vertical distribution usually exceeds radial distribution of water in drip systems, it is important to control the depth of water penetration to eliminate leaching. The use of high emission rates in sandy soils may require short irrigation pulses each day. On the other hand, soils with slow infiltration rates may require low emission rates and longer "on-times." Dripper emission rates commonly vary from 1 to $20 \mathrm{liters} / \mathrm{h}$. The radial water distribution increases with the rate of emission (Bresler, 1977).

The drippers commonly sold on the market today can be categorized into two major groups-pressure- and nonpressure-compensated. In sites with large elevation differences, it is essential to use the pressure-compensated types. Because the rate of water flow in nonpressure-compensated drippers is pressure-dependent, it is important to note that, even on flat land, there is a pressure gradient along the 
line due to resistance. Therefore, the length and diameter of the lines should be taken into consideration when designing microirrigation systems. Therefore, although pressure-compensated drippers are more expensive, they ensure a more-uniform water supply to all trees.

In selecting drippers, considerations such as range of pressures, turbulent flow, and self-cleaning should be taken into account. There are inline drippers as well as drippers of various shapes and forms that are attached externally to the lines. There are also multiple polyethylene tubing "drip tapes," in which water is discharged from small laser-drilled orifices in the tube wall. There are also thin-wall drip tapes with various types of emitters that have relatively short life. The in-line drip tubing has an advantage because rolling off premounted external drippers in large orchards is more difficult.

Drippers can be hung on wires, laid on the soil surface, or buried. Hanging offers the advantage of easy and convenient soil management, but it is more expensive, evaporation losses are greater, and special care needs be taken to prevent "bowing," because in many systems water will drip from the lower point of the bow rather than right under the dripper, and the irrigation depth will fluctuate and be harder to control.

There is a trend towards burying drip systems in orchards. The depth of burying varies between 25 and $65 \mathrm{~cm}$. Although this method offers many cultural advantages and possibilities for maximum water use efficiency, there are also a few problems. In sandy soils, where lateral and upward movement of water is limited, difficulties often occur for newly planted trees until contact is made between the roots and the wetted soil. The danger for moving water and minerals to layers below the root zone is also greater. Clogging of drippers due to root intrusion may cause serious problems. The most-efficient way to inhibit roots is to inject a herbicide that moves slowly in the soil and kills root tips in a small volume around the drippers. Unfortunately, such herbicides are not registered in the United States for injection into drip irrigation systems. Some herbicides embedded in the plastic emitter are registered. Chlorination, as well as phosphoric acid injection at low con- centrations, can minimize root intrusion. In any case, chemicals must be injected above the filters.

Clogging of drip irrigated systems. Clogging can be caused by physical, biological, or chemical factors. Clogging is the most chronic and serious problem facing drip irrigation users. It is extremely important to monitor continuously the water flow and the total application rates, because this is the most-efficient indicator of clogging in pressure-compensated emitters. Particles can be removed efficiently by the use of filtration systems. Filtration technology is well-developed today, and there are engineering solutions to almost all kinds of physical clogging.

Media filters filled with gravel and sand are commonly used with automated back-flushing and are recommended for water high in organic matter and fine soil particles. Screen and ring filters are available for various flow rates, and hydrocyclones are efficient removers of heavy particles such as sand.

Algae are the most common clogging agents in canal or reservoir water, whereas iron bacteria often are found in iron-containing well water. Chlorination of the water in the reservoir followed by media filtration is the most efficient way to handle this situation. Continuous or occasional chlorine injection into the irrigation system at concentrations from 2 to $10 \mathrm{ppm}$ free chlorine for mild and severe cases, respectively, are used commonly. In case of clogging, drippers should be sampled and the cause and treatment determined. In most cases, phosphoric or hydrochloric acid injection at concentrations of $0.6 \%$ to $1.0 \%$ for 10 to 20 min effectively solves the problem. Most irrigation systems tolerate this treatment. In case of a need for a more severe acid treatment, the suitability of the system to that treatment should be verified because considerable differences between filters, valves, and other system components exist.

Phosphoric acid has the advantage of serving as a fertilizer as well, whereas hydrochloric acid may be more efficient in treating biological materials as well as some chemical precipitates, such as $\mathrm{CaCO}_{3}$. Although it is advisable to consult experts for such problems, it is important to bear in mind that growers can sometimes solve these problems by cutting out and removing a few meters of the problematic sections of the irrigation system for detailed investigation. Growers must check the cleaning efficiency of various injection procedures and combinations.

Chemical clogging is very likely to occur when water with high mineral content or high $\mathrm{pH}$ is used. In such cases it is essential to leach the irrigation system for about half an hour prior to and following the fertilizer injection period. When using low-quality water, it is essential either to consult experts regarding rates and kinds of fertilizers or to precheck for possible precipitates the formulations planned by letting it to settle overnight in a separate tank. Reducing the $\mathrm{pH}$ of the water to levels below neutral by injecting low-pH fertilizer solutions is essential in many cases. However, continuous use of extremely low-pH fertilizer over the years may result in reduced soil $\mathrm{pH}$ under the drippers, which might be beneficial for calcareous soils but detrimental for others.

\section{Irrigation scheduling- resolved and unresolved problems}

For many years, it commonly was believed that the correct way to irrigate fruit trees was to apply water uniformly to the entire root system. Uniform distribution of water was a major requirement for any commercially available irrigation water application device. The irrigation frequencies in all of these conventional irrigation methods are determined according to water availability in the soil, but the threshold of water availability to fruit trees is still under debate. In fact, most of our concepts of irrigation were derived from field crops. Hendrickson and Veihmeyer (1950) claimed that all the water between field capacity and wilting point is readily available for trees, implying that water should not be applied before most of the available soil water is depleted. Other workers did not agree with this, and recipes such as $50 \%$ or $30 \%$ available water calculated for the entire profile of 5 or $7 \mathrm{ft}$ were advocated as thresholds for irrigation (Assaf et al., 1974). Most early publications on irrigation scheduling ignored factors such as the hydraulic conductivity of the soil (which determines the rate of water flow from the soil to the roots), root density and distribution (which determines the ef- 
ficiency of water uptake from a given volume of soil), and, to some extent, the evaporative demands (which determine the rate of water loss from the canopy to the atmosphere). When water is absorbed by roots, the immediate vicinity of the roots is depleted and further uptake depends on water gradients for movement in the soil. Therefore, plants grown in mild climates with low evaporative demands, in soils enabling faster water movement, with a dense root system (which does not require long-distance water movement in the soil) are likely to have higher available soil water thresholds for irrigation than plants grown under opposite conditions. The latter might show incipient wilting symptoms, even when the average soil moisture content is high.

Averaging soil water content of the entire soil profile for scheduling irrigation seems to be meaningless for microirrigation systems because water uptake is normally faster from the upper soil layers, and water uptake from the lower layers increases progressively as water in the upper layers is depleted. Therefore, scheduling irrigation according to the average soil water content of the entire profile may lead to irrigation of lower soil layers, which already are sufficiently moist and sometimes too wet. This may lead to water percolation to layers below the root zone, thereby wasting water and fertilizers and contaminating the underground water reservoirs.

Using ET for scheduling irrigation does not necessarily overcome this problem because ET values are based mainly on meteorological data, and the plant canopy factor is not easy to evaluate accurately and is subject to errors. Monitoring the soil water potential (SWP) of deep soil layers throughout the irrigation season by means of either tensiometers or neutron probe readings provides efficient means for optimizing irrigation scheduling. Irrigating the lower soil layers only when deficit is apparent was found to promote root development across the entire profile, and increase water use efficiency, yield, and quality of fruit (Assaf et al., 1974).

\section{Conclusions}

Drip irrigation opens new possibilities for fruit tree growing because it provides means for controlling a few major processes such as water and mineral availability and uptake, as well as root activity. A correct use of drip systems requires different approaches than those used in conventional irrigation systems. In order to succeed with drip, it is essential to fertilize through the system, think in terms of concentrations rather than amounts of fertilizer application, irrigate at frequent intervals, adopt the correct type of emitters and spacing to soil type and topography, control the irrigation depth, and control the vegetative growth and adjust it to the crop level at various stages of fruit development.

Correct use of drip can save water, reduce groundwater pollution, and improve water use efficiency and harvest index.

\section{Literature Cited}

Assaf; R., B. Bravdo, and I. Levin. 1974. Effect ofirrigation according to water deficit in two different soil layers on yield and growth of apple trees. J. Hort. Sci. 49:5364.

Assaf; R., I. Levin, and B. Bravdo. 1985. Effect of drip irrigation on yield and quality of Golden Delicious and Jonathan apples. J. Hort. Sci. 59:493-500.

Assaf, R., L. Levin, and B. Bravdo. 1988. Optimization of water for fruit trees by a computerized irrigation system. Agronomie 9:1-6.

Bravdo, B., Y. Hepner, C. Loinger, S. Cohen, and H. Tabacman. 1985. Effect of crop level on growth, yield and wine quality of a high yielding Carignan vineyard. Amer. J. Enol. Viticult. 35:1247-252.

Bravdo, B. and Y. Hepner. 1987. Irrigation management and fertigation to optimize grape composition and vine performance (review). Acta Hart. 206:49-67.

Bravdo, B., I. Levin, and R. Assaf: 1992. Control of root size and root environment of fruit trees for optimal fruit production. J. Plant. Nun. 15:699-712.

Bresler, E. 1977. Trickle drip irrigation: Principles and application to soil-water management. Adv. Agron. 29:343-393.

Davies W.J. and J. Zhang 1991. Roots signals and the regulation of growth and development of plants in drying soil. 1991. Annu. Rev. Plant Physio1. 42:55-76.

Ein Gal, I. 1979. Effect of drip irrigation regimes on yield, growth, and a few physiological parameters. MS thesis. Hebrew Univ. of Jerusalem, Israel.
Epstein, E. 1972. Mineral nutrition ofplants: principles and perspectives. Wiley, New York. p. 126.

Ferree, D.C. 1980. Canopy development and yield efficiency of "Golden Delicious" apple trees in four orchard management systems. J. Amer. Soc. Hort. Sci. 105:376380 .

Hendrickson, A.H. and F.J. Veihmeyer. 1950. Irrigation experiments with apricots. Proc. Amer. Soc. Hort. Sci. 55:1-10.

Kliewer, W.M. and R..J Weaver. 1971. Effect of crop level and leaf area on growth, composition, and coloration of 'Tokay' grapes. Amer. J. Enol. Viticult. 22:172177.

Levin, I., R. Assaf, and B. Bravdo. 1979. Soil moisture and root distribution in an apple orchard irrigated by tricklers. Plant \& Soil 52:31-40

Middleton, J.E., E.L. Proebsting, and S. Roberts. 1979. Apple orchard irrigation by trickle and sprinkler. Amer. Soc.. Trans. p. 582-543.

Phene, C.J. and O.B. Beale. 1976. High frequency irrigation for water nutrient management in humid regions. Soil. Sci. Soc. Amer. J. 40:430-436.

Rausbkolb, R.S., D.E. Ralston, R.J. Miller, A.B. Carlton, and R.G. Burau. 1976. Phosphorous fertilization with drip irrigation. Soil. Sci. Soc. Amer. J. 40:68-72.

Richards, D. 1986. Tree growth and productivity-the role of roots. Acta Hort. 175:27-36.

Safran B., B. Bravdo, and Z. Bernstein. 1975. Irrigation de la vigne par goutte a goutte. Bul. O.I.V. 48-31:405-429.

Salomon, E. 1978. Induction of dwarfing and early cropping through root treatments in citrus. Acta Hort. 65:147.

Taylor, R.M. and L.B. Fenn. 1985. Translocation of water within root systems of pecan, grape and tomato. HortScience 20:104-105.

Uriu, K., R.M. Carlson, D.W. Henderson, and T.M. Aldrich. 1980. Potassium fertilization of prune trees under drip irrigation. J. Amer. Soc. Hort. Sci. 105:508-510.

Van Zyl, J. 1984. Responses of colombar grapevines to irrigation as regards quality aspects and growth. S. Africa J. Enol. Viticult. 5:19-28. 